\title{
Nature đăng bài tác giả Việt
}

\author{
Nguyễn Minh Hoàng \\ Ritsumeikan Asia Pacific University
}

Ngày 14 tháng 6 năm 2020

Ngày 8-6 vừa qua, tạp chí Nature danh tiếng, 151 tuổi, một trong số rất ít ngọn hải đăng của khoa học nhân loại đã xuất bản bài của TS. Vương Quân Hoàng, Trung tâm ISR (trường Đại học Phenikaa, Hà Nội).

Bài đăng có tựa đề "Reform retractions to make them more transparent" [1], trên Tập 582, Số 7811, doi: 10.1038/d41586-020-01694-x (xem hình).

\section{nature}

WORLD VIEW · 08 JUNE 2020
Subscribe

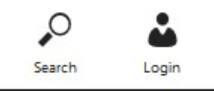

\section{Reform retractions to make them more transparent}

The scientific community should agree on the essential information to

be provided when pulling a paper from the scientific literature.

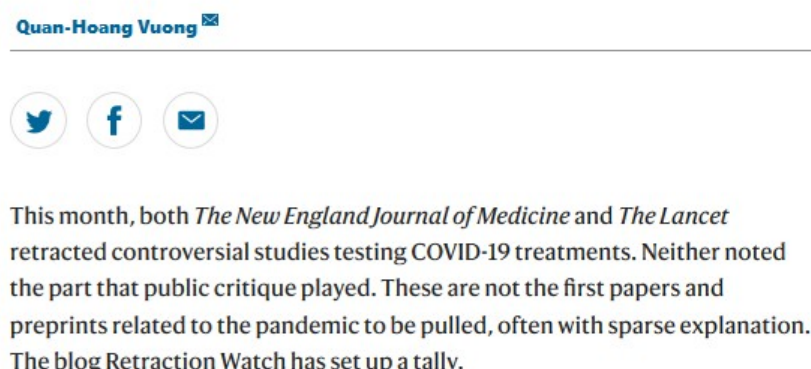

The blog Retraction Watch has set up a tally.

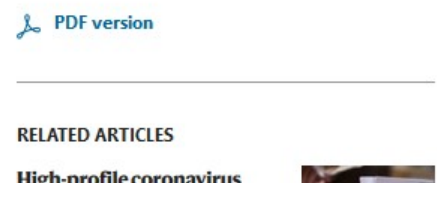

URL: https://www.nature.com/articles/d41586-020-01694-x

Đây là một kết quả trong xê-ri các vấn đề được nhóm nghiên cứu tiến hành tổ chức dữ liệu và triển khai trong nhiều tháng kể từ đầu năm 2019 [2,3].

Tạp chí Nature bên cạnh uy tín hàng đầu thế giới, thì cũng có hệ số tác động (JIF của Clarivate ISI Web of Science) rất cao, $\mathrm{JIF}_{2018}=43.07$. Nature có $h$-index theo SCImago 2019 ở mức "khủng", 1159 [4]. 


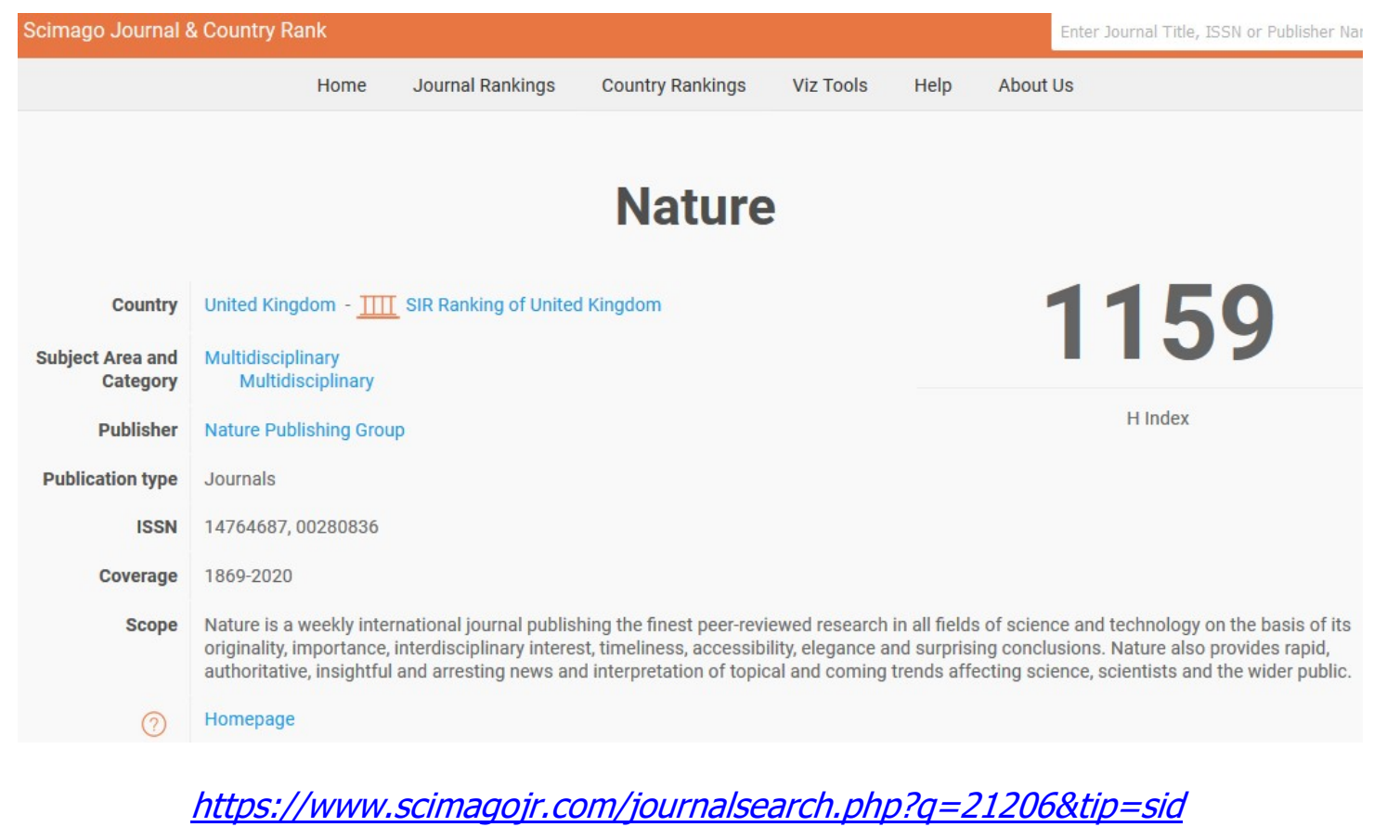

Chỉ có một số rất ít các tạp chí khoa học tổng quát khác có thể sánh ngang về uy tín hàn lâm với Nature. Tiêu biểu là tạp chí lừng danh Science (www.sciencemag.org), ấn phẩm của AAAS do hai thiên tài phát minh, Thomas Edison và Alexander Graham Bell, hậu thuẫn. Tạp chí Science đã được ấn hành liên tục trong suốt 140 năm, với hệ số tác động $\mathrm{JIF}_{2018} 41.037, h$ index 1124 (SCImago 2020). Kế đến, phải nhắc tới Kỷ yếu Viện hàn lâm khoa học Hoa Kỳ lừng lẫy, với tên viết tắt quen thuộc PNAS (www.pnas.org), ẫn phẩm chính thức của Viện Hàn Lâm KH Mỹ, ân phẩm cũng đã được ấn hành liên tục suốt 105 năm, có JIF $F_{2018} 9.58$, h-index 737 (SCImago 2020).

Bài báo cũng được rất nhiều các nhà khoa học và cộng đồng truyền thông khoa học chia sẻ trên Twitter, blogs và các website đại học. Hệ thống theo dõi ảnh hưởng truyền thông Altmetric của Digital Science (https://www.digital-science.com) cho biết, tính tới 14-6, sau gần một tuần xuất bản, bài báo có số điểm Altmetric 164, nằm trong top 5\% ảnh hưởng của hơn 15 triệu ấn phẩm khoa học mà hệ thống lưu trữ dữ liệu. 

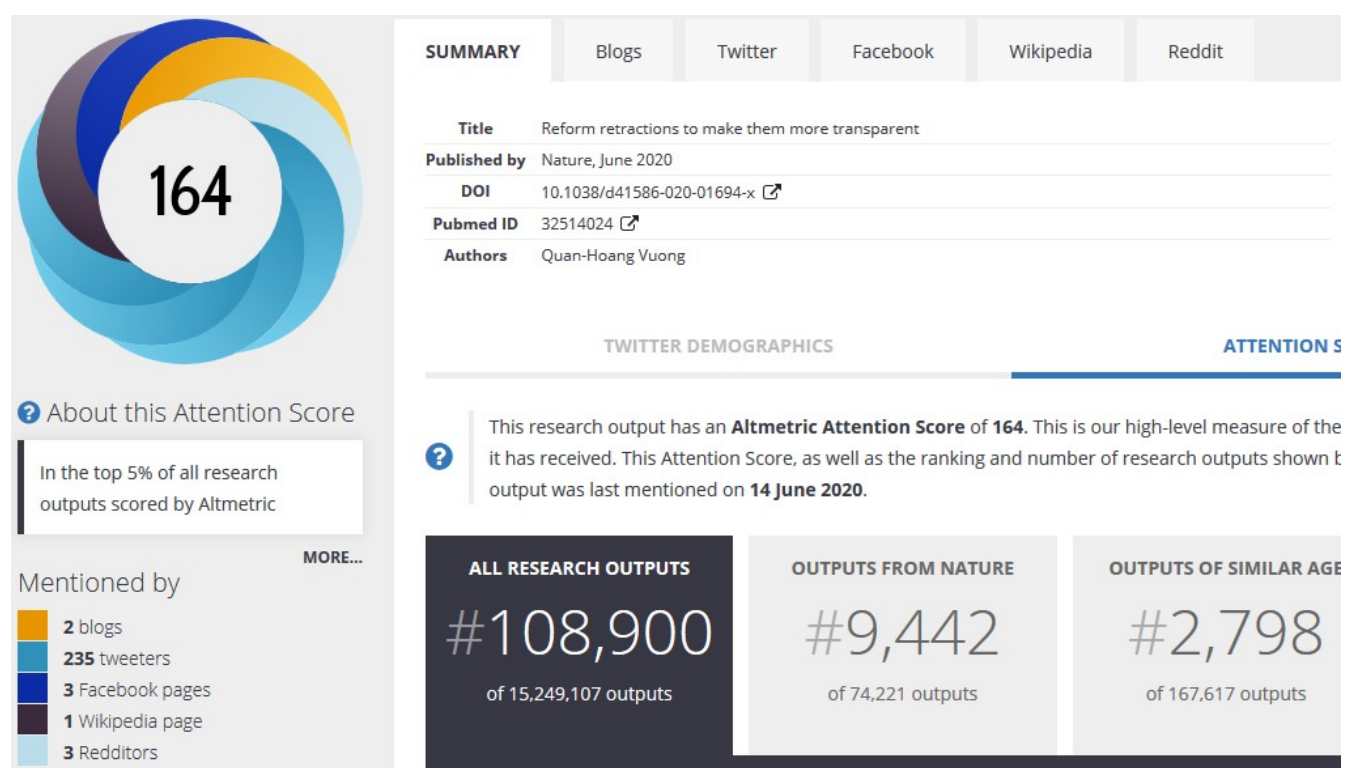

Altmetric tính đến 11:00 PM ngày 14-6-2020

Trước bài này, các bài đăng trên tạp chí có JIF cao nhất của KHXH Việt Nam cũng thuộc về TS. Vương Quân Hoàng, đều trên tạp chí của Nature Research Nature Human Behaviour (https://www.nature.com/nathumbehav), $\mathrm{JIF}_{2018}=10.575$, trong các năm 2018 và 2019 [5,6].

\section{Tài liệu tham khảo:}

[1] Vuong, Q. H. (2020). Reform retractions to make them more transparent. Nature, 582(7811), 149.

[2] Vuong, Q. H., La, V. P., Ho, M. T., Vuong, T. T., \& Ho, M. T. (2020). Characteristics of retracted articles based on retraction data from online sources through February 2019. Science Editing, $\pi 1), 34-44$.

[3] Vuong, Q. H. (2020). The limitations of retraction notices and the heroic acts of authors who correct the scholarly record: an analysis of retractions of papers published from 19752019. Learned Publishing, 33(2), 119-130.

[4] SCImago. (2020). Nature. https://www.scimagojr.com/journalsearch.php?q=21206\&tip=sid

[5] Vuong, Q. H. (2019). Breaking barriers in publishing demands a proactive attitude. Nature Human Behaviour, 3(10), 1034.

[6] Vuong, Q. H. (2018). The (ir)rational consideration of the cost of science in transition economies. Nature Human Behaviour, 2(1), 5. 